\title{
LA POLÍTICA EUROPEA DE VECINDAD HACIA EL MEDITERRÁNEO (2003-2015): IMPOTENCIA DE LA UNIÓN EUROPEA ANTE UN ENTORNO CADA VEZ MÁS HOSTIL
}

\author{
Mercedes Guinea ${ }^{1}$ \\ UNISCI / Universidad Complutense de Madrid (UCM)
}

\begin{abstract}
Resumen:
En marzo de 2015, la nueva Comisión Europea ha convocado una revisión de la Política Europea de Vecindad. En este contexto conviene realizar una evaluación de la PEV de la UE hacia el Mediterráneo, desde sus orígenes hasta nuestros días. Ese estudio de la PEV se ceñirá especialmente a su modelo y características principales, abordando la doble dimensión bilateral y la multilateral puesta en marcha con el proyecto de Unión para el Mediterráneo, lanzado en el año 2008. Prestaremos especial atención a los últimos desarrollos y reconducciones, especialmente los causados por las Primaveras Árabes y la incapacidad de la UE de ofrecer respuestas a esos desafíos políticos.
\end{abstract}

Palabras clave: Unión Europea, Mediterráneo, Política Europea de Vecindad, Unión para el Mediterráneo.

Title in English: "The European Union's Neighbourhood Policy towards the Mediterranean (20032015): The European Union's Impotence in an Increasingly Hostile Environment"

\begin{abstract}
:
In March 2015, the new elected European Commission has called a thorough revision of the European Neighbourhood Policy (ENP). In this context, an assessment of the ENP towards the Mediterranean is urgently needed. This analysis will address specifically its political model and characteristics, taking into account its twin dimension, bilateral and multilateral, and further developments as the Union for the Mediterranean in 2008. The European institutions reacted to the Arab Springs events with a deep reform of the ENP, which will be assessed, assuming its shortcomings to ensure a solid stance for the EU in the region.
\end{abstract}

Keywords: European Union, Mediterranean, European Neighbourhood Policy, Union for the Mediterranean.

Copyright (C) UNISCI, 2015.

Las opiniones expresadas en estos artículos son propias de sus autores, y no reflejan necesariamente la opinión de UNISCI. The views expressed in these articles are those of the authors, and do not necessarily reflect the views of UNISCI.

\footnotetext{
${ }^{1}$ Mercedes Guinea Llorente es Profesora de Relaciones Internacionales de la Universidad Complutense de Madrid, titular del Módulo Europeo Jean Monnet de la Comisión Europea sobre "La aplicación del Tratado de Lisboa: efectos en el modelo político, económico y social". Es igualmente investigadora senior de UNISCI y miembro del Foro Hispano-Argelino.

Dirección: Departamento de Estudios Internacionales, Facultad de Ciencias Políticas y Sociología, UCM, Campus de Somosaguas, 28223 Madrid, España.

Email: mercedes.guinea@,telefonica.net.
}

http://dx.doi.org/10.5209/rev_RUNI.2015.n39.5180u 


\section{Introducción}

En el presente trabajo nos proponemos presentar unas breves reflexiones sobre la Política Europea de Vecindad hacia el Mediterráneo, desde sus orígenes hasta nuestros días. Ese estudio de la PEV se ceñirá especialmente a su modelo y características principales, abordando la doble dimensión bilateral y la multilateral puesta en marcha con el proyecto de Unión para el Mediterráneo, lanzado en el año 2008. Prestaremos especial atención a los últimos desarrollos y reconducciones, especialmente los causados por las Primaveras Árabes y la incapacidad de la UE de ofrecer respuestas a esos desafíos políticos. La evaluación, tanto del marco político como de su implementación y resultados, nos lleva a formular la hipótesis de una fragmentación de la política, que no permitirá que se hable de un Vecindario Sur uniforme. Este enfoque se percibe en las nuevas propuestas, destacando las que señalan la necesidad de que la UE concentre sus esfuerzos en el Magreb.

Intentaremos realizar una evaluación de la eficacia de la PEV, a partir del examen y confrontación de los objetivos marcados desde la política europea y los resultados constatables. Esa evaluación se realizará a partir de los informes anuales aprobados por las propias instituciones europeas y su control político por el Parlamento Europeo y de análisis independientes procedentes de la doctrina y de "think-tanks".

Se coincide, aunque desde posiciones muy diversas y por razones diferentes, en que la PEV europea se encuentra muy lejos de alcanzar los objetivos que se dio a sí misma. Cabe, por tanto, preguntarse cuáles son los factores y las causas que explican, desde un punto de vista interno, el fracaso de la PEV hacia el Mediterráneo. Cabe aquí señalar que nos vamos a ceñir a un análisis de la propia UE y su política exterior, sin tener en cuenta la relevancia y acción de otros actores internacionales como elemento central de nuestro estudio.

Esta indagación quiere abordar una doble dimensión. Primero, la correspondiente a la propia condición de actor internacional de la UE y a la constatación de su debilidad en el ámbito de la Política Exterior y de Seguridad Común, al no contar con competencias propias, sino ser simplemente un policy-agent que trata de conciliar las voluntades de sus estados miembros. La hipótesis que aventuraremos en este ámbito es que la debilidad de la UE se basa en los intereses divergentes entre sus estados miembros y la dificultad de formular una política común hacia el Mediterráneo, en consecuencia.

En segundo lugar, estudiaremos la política formulada hacia el Mediterráneo, sus fortalezas y debilidades. Como hipótesis de trabajo provisional, consideramos que el principal problema de la PEV, común a la formulada hacia el Este de Europa, es que parte de unas proposiciones idealizadas que no responden a la realidad y que es rechazada por algunos de sus destinatarios al ser considerada un vehículo de transmisión de valores ajenos, una suerte de "imperialismo suave". Igualmente, consideramos que es una política pobremente dotada, y que los recursos que ha recibido en el pasado desmienten la prioridad que formalmente le otorgan las instituciones comunes.

Sólo desde los factores y las causas que explican las limitaciones de la PEV pueden abordarse los desafíos de futuro y las respuestas que puedan plantearse desde una renovación de la Política Europea hacia el Mediterráneo. Intentaremos, por tanto, al final de este artículo identificar los elementos políticos que requieren una respuesta por parte de la UE y las posibles alternativas a las que se enfrenta. 


\section{La política europea hacia el Mediterráneo: Política europea de vecindad, Unión para el Mediterráneo y reforma tras la primavera árabe}

Las relaciones preferenciales de la Comunidad/Unión Europea con el Mediterráneo datan de los años 70 pero encontraron su punto álgido con el Proceso de Barcelona que estableció una Asociación Euro-mediterránea en 1995, a iniciativa española ${ }^{2}$. Esta asociación privilegiada, puesta en marcha con los estados de la orilla sur y este del Mediterráneo planteó altas ambiciones en torno a tres áreas o "cestas" de cooperación (seguridad, economía y cultura y sociedad) y presentó resultados desiguales ${ }^{3}$.

En materia de seguridad, apenas se avanzó en la consecución de un área de paz y estabilidad, debido, sobre todo, a la contaminación de la Asociación por parte del conflicto palestino-israelí, la falta de cohesión de todos los estados miembros en torno a este tema y el seguidismo de la UE de las políticas impulsadas desde Estados Unidos ${ }^{4}$. Desde el punto de vista económico, no se cumplió con el objetivo del área de librecomercio para 2010, pero la Asociación promovió la modernización de las estructuras económicas de los estados mediterráneos y el incremento de flujos comerciales entre las dos orillas, si bien desde estos países se criticaba las limitaciones en materia de importaciones de productos agrícolas y textiles al mercado comunitario y las barreras a la libre circulación de personas ${ }^{5}$. No obstante, la AEM presentó algunos logros positivos menores: como la creación de un marco formal de diálogo político y de dinámicas de cooperación, el impulso de algunas reformas económicas y el intento de acercamiento de culturas ${ }^{6}$. Sin embargo, la brecha económica con el Mediterráneo se abrió y el diálogo político no era profundo.

En 2003 se utiliza la Política Europea de Vecindad (PEV) para intentar revitalizar un marco que no funciona. Esta política, lanzada en el momento en que culminaba la gran ampliación hacia los países del Centro y Este de Europa, se dirigía tanto a los países del Mediterráneo y Norte de África (MENA) como a los de Europa Oriental y el Cáucaso Sur. En el caso del Mediterráneo, en 2008 sería creada la Unión por el Mediterráneo, que pretendía diferenciar los dos vecindarios europeos, a la vez que dotar de una institucionalidad común para una coapropiación y un marco especial para el desarrollo de proyectos conjuntos. Las Primaveras Árabes de 2011 conducirían a una revisión de la política, que más que tocar sus fundamentos supondría una adaptación de principios e instrumentos.

\footnotetext{
${ }^{2}$ En el momento álgido de la influencia española en la Unión Europea, uno de los objetivos de la Presidencia semestral española de julio a diciembre de 1995 fue la convocatoria de la Conferencia Euromediterránea de Barcelona, que reuniría a los representantes de los 15 estados miembros con los de 12 estados de las dos orillas del Mediterráneo. Se pondría en marcha la Asociación Euromediterránea o Proceso de Barcelona, marco multilateral permanente de cooperación con el objetivo de "hacer de la cuenca mediterránea un ámbito de diálogo, intercambio y cooperación que garantice la paz, la estabilidad y la prosperidad". Véase: Conferencia Euromediterránea, Declaración de Barcelona, Barcelona, 22-25 de noviembre de 1995, p. 2.

${ }^{3}$ En relación a la Asociación Euro-mediterránea, véase: Strademed (1997): Méditerranée, le Pacte à construiré, Paris, Publisud; Brauch, Hans Günter, Marquina, Antonio, Biad Abdelwahab (eds.) (2000): Euro-Mediterranean Partnership for the 21st Century, Basingstoke, Macmillan Press; Strademed (2000): Euro-Méditerranée, 1995 1999. Premier Bilan du Partenariat, PDCM, Toulon; Blanc Altemir, Antonio (ed.) (1999): El Mediterráneo: un espacio común para la cooperación, el desarrollo y el diálogo intercultural, Madrid, Tecnos; Khader, Bichara (2009): Europa por el Mediterráneo: de Barcelona a Barcelona (1995-1999), Barcelona, Icaria; Filali, Osman y Philip, Christian (eds.) (2003): Le partenariat euro-méditerranéen. Le processus de Barcelone: Nouvelles perspectives, Bruxelles, Bruylant.

${ }^{4}$ Aliboni, Roberto (2005): "10 ans de dialogue politique et de sécurité au sein du processus du Barcelone: une tentative d'évaluation", Géoéconomie, no 35 pp. 101-121.

${ }^{5}$ Ben Yahia, Aviv (2003): "El diálogo euro-mediterráneo y los conflictos regionales", Real Instituto Elcano, ARI 148/2003, 22 de abril.

${ }^{6}$ Blanc Altemir, Antonio (2012): La Unión Europea y el Mediterráneo. De los primeros acuerdos a la Primavera Árabe, Madrid, Tecnos, p. 125.
} 


\subsection{Gestación de la Política Europea de Vecindad y su extensión hacia el Mediterráneo}

Sobre la Asociación Euro-mediterránea y como un añadido a la política, se planteó la PEV por la Comisión en 2003, que pretendía crear alrededor de la Unión un área de estabilidad, a través de la exportación de los valores europeos a los vecinos y su integración en las estructuras económicas de la $\mathrm{UE}^{7}$. La PEV se apoyaba en la presunción de que los estados vecinos, con limitaciones serias en términos de gobernanza institucional y democracia, accederían a emprender las costosas reformas que la UE les propondría atraídos por el halagüeño panorama de la participación en los beneficios de relaciones más estrechas y preferenciales con la UE, el acceso a grandes fondos de cooperación, y en última instancia, la integración en el mercado y las políticas económicas europeas ${ }^{8}$. Con la finalidad de que las nuevas fronteras que dibujaría la ampliación no actuaran como nuevas líneas divisorias, la importancia que recibe esta política hará que se incluya, incluso, un nuevo artículo en el TUE 9 .

El contexto en el que se gesta esta política es la euforia por el éxito transformador de la ampliación a los países europeos del otro lado del Telón de Acero y la creencia de que se podía trasladar el mismo método para enfrentar las demandas de seguridad de las nuevas fronteras de la UE. Así, la Estrategia Europea de Seguridad redactada en la misma época en que se abre el debate político, afirmará que uno de los objetivos estratégicos de la Unión es crear seguridad en sus estados vecinos ${ }^{10}$. Apoyar desde la PEV transiciones democráticas, el

\footnotetext{
${ }^{7}$ Comisión Europea, Comunicación de la Comisión al Consejo y al Parlamento Europeo, "Una Europa más amplia. Relaciones con los países vecinos: un nuevo marco para las relaciones con nuestros vecinos del Este y del Sur de Europa", Bruselas, 11 de marzo de 2003, (COM (2003), 393 final).

${ }^{8}$ Entre los trabajos generales que abordan el estudio de la PEV, podemos destacar los siguientes: Attiná Fulvio y Rossi, Rosa (eds.) (2004): European Neighbourhood Policy: Political, Economic and Social Issues, Catania, Jean Monnet Centre; Beurdeley, Laurent, de la Brosse, Renaud. y Maron, Fabienne (dirs) (2007): L'Union européenne et ses espaces de proximité. Entre stratégie inclusive et parténariats rénovés: quel avenir pour le nouveau voisinage de l'Union?, Bruxelles, Bruylant; Blockmanns Steven y Lazowski Adam. (eds.) (2006): The European Union and Its Neighbours, The Hague, T.M.C. Asser Institut. Debardeleben, Joan (ed.) (2008): The Boundaries of EU Enlargement: Finding a Place for Neighbours, Basingstoke, Palgrave-Macmillan; Cierco, Teresa (ed.) (2013) The European Union Neighbourhood: Challenges and Opportunities, Farnham, Ashgate; Gstöhl, Sieglinde \& Lannon Erwan (eds) (2015): The European Union's Broader Neighbourhood: Challenges and Opportunities for Cooperation beyond the European Neighbourhood Policy, London, Routledge; Labouz, Marie-Françoise, Philip, Christian y Soldatos, Panayotis (dirs.) (2006): L'Union européenne élargie aux nouvelles frontières et à la recherche d'une politique de voisinage, Bruxelles, Bruylant; Noutcheva, Gergana, Karolina Pomorska, and Giselle Bosse (2013): The EU and its neighbours: Values versus security in European foreign policy, Manchester, Manchester University Press; Orozco Torres, Luis.Ernesto (2006): La Nueva Política Europea de Vecindad ¿de la Paneuropa a la Paraeuropa?, Sevilla, Universidad de Sevilla; Smith, Michael, Weber, Katja y Baun, Michael. (eds.) (2007): Governing Europe's Neighbourhood. Partners or Periphery?, Manchester, Manchester University Press; Whitman Richard y Wolff, Stefan (eds.) (2010): The European neighbourhood policy in perspective: context, implementation and impact, New York, Palgrave Macmillan.

${ }^{9}$ El artículo 8 del TUE establece: "1. La Unión desarrollará con los países vecinos relaciones preferentes, con el objetivo de establecer un espacio de prosperidad y de buena vecindad basado en los valores de la Unión y caracterizado por unas relaciones estrechas y pacíficas fundadas en la cooperación. 2. A efectos del apartado 1, la Unión podrá celebrar acuerdos específicos con dichos países. Estos acuerdos podrán incluir derechos y obligaciones recíprocos, así como la posibilidad de realizar acciones en común. Su aplicación será objeto de una concertación periódica".

10 Así afirma: "Los vecinos inmersos en conflictos violentos, los estados débiles en los que prolifera la delincuencia organizada, las sociedades disfuncionales o las explosiones demográficas en nuestras fronteras plantean problemas a Europa. La integración de los estados adherentes aumentará nuestra seguridad, pero también acercará Europa a zonas conflictivas. Nuestra tarea es promover un conjunto de países bien gobernados al este de la Unión Europea y en las orillas del Mediterráneo, con los que podamos mantener unas relaciones estrechas y de cooperación". Consejo Europeo, "Una Europa segura en un mundo mejor". Estrategia Europea de Seguridad, Bruselas, 12 de diciembre de 2003, pp. 7-8.
} 
avance de los derechos humanos y la asunción de los principios de la economía libre de mercado se consideraba una vía efectiva hacia la construcción de estados vecinos más estables. La PEV es, por tanto, una política esencialmente normativa, esto es, dirigida a exportar los valores de la UE a su entorno más inmediato con la finalidad de estabilizarlos ${ }^{11}$.

En las primeras iniciativas, la PEV estaba dirigida a los países de Europa Oriental que en 2004 iban a constituir la nueva frontera de la UE en el Este. No obstante, la insistencia francesa haría que finalmente se incluyera en este marco político a los países del Mediterráneo Sur, su tradicional zona de influencia, para contrarrestar el peso alemán incrementado con la ampliación. Cubriría así a dieciséis países vecinos: tres de Europa Oriental, tres del Cáucaso Sur y diez Mediterráneos ${ }^{12}$. Comenzada a aplicar en el año 2004, utilizando los Acuerdos Euro-mediterráneos como base jurídica, sufriría una adaptación en el año 2007, tras la evaluación de los primeros años de aplicación ${ }^{13}$.

La PEV, desde sus inicios, va a configurarse como una política muy peculiar, con características y mecanismos propios que hacen de ella la política exterior más desarrollada y compleja de las europeas ${ }^{14}$. Entre sus características principales podemos destacar las siguientes ${ }^{15}$ :

1. El estatuto de vecino es un estatuto constitucional permanente a medio camino entre la condición de miembro y la asociación. LA PEV no es una herramienta más de política exterior, como prueba el hecho de que las relaciones con el entorno próximo se regulen en el nuevo artículo 8, entre las Disposiciones Generales del TUE, dedicadas al modelo político de la Unión, y no entre las disposiciones relativas a la Política Exterior $^{16}$. Este estatuto, basado en los valores comunes, permite aplicar la flexibilidad al estatuto de miembro, estableciendo una tercera vía que dibuja en torno a la Unión círculos concéntricos de relación ${ }^{17}$. El vecino se integrará en todas las políticas de la Unión con la sola exclusión de su participación en las instituciones ${ }^{18}$.

2. La PEV es la política transformadora para alcanzar el estatuto de vecino. La PEV persigue que los terceros estados del entorno próximo puedan acceder a la condición de

\footnotetext{
${ }^{11}$ Ghazaryan, Nariné (2014): The European Neighbourhood Policy and the democratic values of the EU: A legal analysis, Oxford, Hart.

${ }^{12}$ Los diez socios mediterráneos a los que se dirige la PEV son: Marruecos, Argelia, Túnez, Libia, Egipto, Israel, Territorios Palestinos Ocupados, Jordania, Líbano y Siria.

${ }^{13}$ Comisión Europea, Comunicación de la Comisión al Parlamento Europeo y al Consejo "Una sólida política de vecindad", 5 de diciembre de 2007, (COM(2007) 774final)

${ }^{14}$ A juicio de Charillon, "Whatever its limits and shortcomings, this policy constitutes a unique collective response to external pressures and demands, as well as exhibiting new forms of collective foreign policy anticipation and implementation". Charillon, F. (2004): "Sovereignty and Intervention: EU's Intervention in its 'Near Abroad'", en: Carlsnaes Walter, Sjursen Helene and White Brian (eds.), Contemporary European Foreign Policy, London, Sage., pp. 252-264.

${ }^{15}$ En otro lugar hemos estudiado las características distintivas de la PEV: Guinea Llorente, Mercedes (2008): "La Política Europea de Vecindad y la estabilización del entorno próximo: el caso de Europa Oriental", Revista de Derecho Comunitario Europeo, n ${ }^{\circ} 31$, pp. 805-831.

16 Véase al respecto: Comelli, Michele.: "Article 8 TEU and the Revision of the European Neighbourhood Policy", en: Rossi Lucia, Serena y Casolari, Federico (eds.) (2014): The EU after Lisbon, Berlin, Springer, pp. 267-289.

17 Aldecoa Luzárraga, Francisco y Guinea Llorente, Mercedes (2008): La Europa que viene: El Tratado de Lisboa, Madrid, Marcial, Pons, pp. 214-216.

${ }^{18}$ El estatuto de Vecino ya existe en la actualidad; estaría conformado por los países que integran el Espacio Económico Europeo (EEE), países que son parte del Mercado Interior y de las políticas de la Unión pero que no participan en las instituciones. En el futuro, existirá una importante diferencia entre estos Vecinos EEE y los Vecinos PEV, y es que éstos se encuentran fuera de las instituciones por elección propia.
} 
Vecinos, nuevo estatuto en el modelo político europeo de geometrías variables ${ }^{19}$. La PEV promete a los estados terceros, en el largo plazo, "la perspectiva de participación en el mercado interior de la UE y de una integración y liberalización mayores para fomentar la libre circulación de personas, mercancías, servicios y capitales" ${ }^{20}$. Esa perspectiva de convertirse en vecino se somete a la adopción de los valores de la Unión. La PEV es la política exterior que, a cambio de incentivos, permitirá a esos estados socios transformarse asumiendo los valores de la Unión ${ }^{21}$.

3. La mecánica propia de la PEV se apoya sobre la condicionalidad positiva. Esta política fue diseñada por la Comisión calcando los procedimientos y los instrumentos de la exitosa política de ampliación: planes de acción consensuados en el seno de las instituciones comunes de los Acuerdos de Asociación, evaluaciones periódicas, unilaterales y consensuadas, y enfoque "regata" o diferenciado para cada país dentro de un marco estratégico común ${ }^{22}$. Se pactan con los terceros estados en el seno de las instituciones conjuntas reformas a llevar a cabo por éstos con el apoyo de la ayuda financiera de la Unión así como otros instrumentos de cooperación y asistencia ${ }^{23}$. El éxito en la consecución de las reformas tiene como consecuencia el estrechamiento en los vínculos con la Unión a través de Acuerdos de Asociación Reforzada y el acceso a otros incentivos, como la participación en programas y agencias comunitarias.

4. La PEV se diseña como una estrategia política transpilar que combina integración económica progresiva con cooperación política. A pesar de estar liderada desde la Comisión, la PEV quería incluir todos los instrumentos de la Unión: los de la PESC y PESD, política comercial, cooperación al desarrollo, integración en las políticas comunes e, incluso, cooperación en justicia y asuntos de interior. Según Lavenex y Schimmelfennig, existe una distinción inherente dentro de la PEV entre los objetivos estratégicos de la promoción de la democracia y la resolución de conflictos; la cooperación sectorial, que ha de ser interpretada como una forma de integración horizontal flexible; y la gobernanza exterior ${ }^{24}$. Esa gobernanza exterior, a su juicio, ha experimentado una evolución, caracterizándose en sus inicios por la expansión de la

\footnotetext{
${ }^{19}$ Cada uno de los Planes de Acción de la PEV comienza con la frase: "La PEV fija objetivos ambiciosos para la asociación con los países vecinos, basada en el compromiso con valores compartidos, objetivos claves de política exterior y reformas políticas, económicas e institucionales". Tómese como ejemplo: Plan de Acción Unión Europea-Moldova, 5 de Febrero de 2005, p. 1.

${ }^{20}$ Comisión Europea, Comunicación de la Comisión al Consejo y al Parlamento Europeo "Una Europa más amplia...", op. cit., p. 4.

${ }^{21}$ En este sentido, a nuestro juicio, la PEV es tanto el proceso de adaptación y cambio de los vecinos como el nuevo estatuto político que se prevé otorgar a los que compartan plenamente los valores de la UE. Haciendo una comparación con las políticas de ampliación, la PEV incluiría tanto el proceso de preadhesión como este nuevo estatuto de cuasi miembro. Hettne no duda en calificar esta estrategia de "imperialismo suave", en la medida en que los vínculos condicionales dependen de una relación asimétrica. Hettne, Björn: "Interregionalism and World Order: The Diverging EU and US Models", en: Teló, Mario (ed.) (2007):, European Union and New Regionalism: Regional Actors and Global Governance in a Post-hegemonic Era, Aldershot, Ashgate, pp. 106123, esp. la p.114.

${ }^{22}$ La PEV fue diseñada desde la DG Ampliación, recogiendo las enseñanzas de esta política y adaptándolas a un contexto post-ampliación. Puede, incluso, verse como un intento fructífero de la Comisión por seguir controlando parte de la Alta Política Exterior europea. Vid. Kelley Judith (2006): "New Wine in Old Wineskins: Promoting Political Reforms through the New European Neighbourhood Policy", Journal of Common Market Studies, vol. 44, no 1, pp. 29-55.

${ }^{23}$ La financiación se canaliza a través de un fondo específico, denominado Instrumento Europeo de Vecindad que, en el periodo 2014-2020 ha previsto un total de 15.432,6 millones de euros. Véase: Reglamento UE $n^{\circ}$ 232/2014, del Parlamento Europeo y del Consejo, de 11 de marzo de 2014, por el que se establece un Instrumento Europeo de Vecindad, DO L 77, de 15.3.2014, p. 27.

${ }^{24}$ Lavenex, Sandra, y Schimmelfennig, Frank (2007): "Relations with the Wider Europe", Journal of Common Market Studies, vol. 45, Annual Review, pp. 143-162, especialmente pp. 151-152.
} 
normativa europea y pasando ahora a la participación parcial de los países en las políticas y agencias europeas.

5. La PEV se caracteriza por ser un marco multilateral para una relación bilateral a la que se añade también una dimensión regional. La PEV se formula en su concepción estratégica como un marco común para un total de dieciséis países, tan dispares como los de Europa Oriental, el Cáucaso Sur y el Mediterráneo ${ }^{25}$. Sin embargo, la aplicación de la PEV se hace a la medida, caso por caso, en el marco de una relación bilateral con el estado concernido. En 2006 la Comisión planteó la necesidad de añadir una dimensión regional a la política, con iniciativas de cooperación Sur-Sur para abordar problemas comunes, en ámbitos como el transporte, la migración o la investigación. Junto a estos planos que podemos llamar "gubernamentales", desde 2006 la Comisión ha llamado la atención sobre la necesidad de desarrollar un enfoque "bottom-up", esto es, contactos directos entre las sociedades civiles, a fin de aprovechar los beneficios de la socialización. Esa regionalización se consolidaría con la puesta en marcha en 2008 de la Unión para el Mediterráneo y la Asociación Oriental, ésta última para los países de Europa del Este y el Cáucaso Sur ${ }^{26}$.

\subsection{La Unión para el Mediterráneo: la dimensión multilateral que se suma a la bilateral}

La dimensión bilateral de la PEV fue complementada a través de la Unión para el Mediterráneo (UpM) de 2008, que dota de una dimensión multilateral y una regionalización expresa a la política europea hacia el Mediterráneo ${ }^{27}$. Se añade así una nueva capa sobre la Asociación Euromediterránea y la PEV a la estrategia europea hacia el Mediterráneo. En ese sentido, la UpM constituye una etapa y un nivel más de la política mediterránea de la UE, en una reacción intergubernamental al evidente fracaso de la $\mathrm{PEV}^{28}$. Cuando se encontraba en campaña electoral para las elecciones presidenciales, Nicolas Sarkozy en un mitin en Toulon en 2007 lanzó la idea de crear una Unión Mediterránea. Concebía esta como una organización internacional específica, conformada por los estados europeos mediterráneos y los de la rivera Sur del Mediterráneo, que trabajara codo con codo con la UE y que tuviera la finalidad de establecer una estrecha asociación para abordar los desafíos comunes y la inserción de los países del Sur en la globalización ${ }^{29}$.

Elegido Presidente, Sarkozy llevó su iniciativa a sus socios europeos, quienes tras variados debates aceptaron asumir ese proyecto incluyéndolo en el marco del Proceso de

\footnotetext{
${ }^{25}$ Ese carácter multilateral puede verse, por ejemplo, en la convocatoria de la primera Conferencia sobre la PEV el 3 septiembre de 2007, en el seno de la cual representantes de los distintos países parte debatieron este marco político y presentaron sus demandas a la Unión.

${ }^{26}$ Con la puesta en marcha de estas dos iniciativas de regionalización, se abandonaría expresamente la dimensión multilateral de la PEV.

${ }^{27}$ En relación a la Unión por el Mediterráneo, véase: Barbé, Esther (2009): "La Unión por el Mediterráneo: de la europeización de la política exterior a la descomunitarización de la política mediterránea", Revista de Derecho Comunitario Europeo, no 32, pp. 9-46; Blanc Altemir Antonio, La Unión Europea y el Mediterráneo..., op. cit., pp. 165-194; Granell, Francesc (2013), "La Unión por el Mediterráneo como organismo internacional y como catalizadora de la cooperación europea", Revista de Derecho Comunitario Europeo, no 46, pp. 1033-1059; Huici Sancho, Laura (coord.) (2011): La Unión por el Mediterráneo: retos de la cooperación institucionalizada en la región, Madrid, Marcial Pons; Khader, Bichara (2009): Europa por el Mediterráneo. De Barcelona a Barcelona (1995-2009), Barcelona, Icaria. Reiterer, Michael (2009): "From the (French) Mediterranean Union to the (European) Barcelona Process: The "Union for the Mediterranean" as part of the European Neighbourhood Policy", European Foreign Affairs Review, vol. 14, n 3, pp. 313-336;

${ }^{28}$ Kochenov, Dimitry (2011): "New Developments in the European Neighbourhood Policy: Ignoring the problems", Comparative European Politics, vol. 9, no 4/5, pp. 581-595, p. 583.

${ }^{29}$ Véase: Sarkozy, Nicolas (2007): Discours à Toulon, 7 février.
} 
Barcelona, como una etapa de mayor profundización de la política común europea ${ }^{30}$. Esa transformación, en la que tuvo un protagonismo relevante el Ministro de Exteriores español Moratinos, supuso una dilución del intento de revitalización de Sarkozy, de cuya iniciativa sólo quedarían los proyectos comunes. Cambiado su nombre por Unión para el Mediterráneo, su contenido e innovaciones fue consensuado con los estados socios mediterráneos en el seno de la Cumbre de París, convocada por la Presidencia francesa ${ }^{31}$. Meses después, en una reunión ministerial conjunta en Marsella se acabarían de perfilar los contenidos de esta nueva adición a la cooperación europea con los países de la ribera Sur del Mediterráneo y se elegiría Barcelona como sede de las nuevas instituciones. Se pasa así del modelo inicial de cooperación reforzada en política exterior, con sólo algunos estados de la UE implicados, al resultado final de una regionalización de la PEV de la UE.

La UpM presenta la innovación de constituirse como un organismo internacional intergubernamental, conformado por los estados miembros participantes y la UE, lo que presenta la ventaja de poder buscar recursos financieros adicionales fuera del presupuesto de la $\mathrm{UE}^{32}$. En la UpM participan un mayor número de estados que en la tradicional Asociación Euromediterránea: la UE y sus 28 estados miembros, 4 países de la orilla Norte candidatos a ser miembros de la UE (Albania, Bosnia-Herzegovina, Montenegro y Turquía), un estado europeo asociado (Mónaco), 9 de los socios del Sur de la Asociación Euromediterránea (Marruecos, Argelia, Túnez, Egipto, Israel, Territorios Palestinos Ocupados, Líbano, Jordania y Siria) y Mauritania. Libia y la Liga Árabe tienen el estatuto de observadores ${ }^{33}$.

La UpM quiere ser un nuevo impulso en una asociación mediterránea que se consideraba que se encontraba, en buena medida, estancada. Este marco incluye dos objetivos y dos grandes adiciones. Los objetivos son reforzar la coapropiación por parte de los estados del Sur e intentar promover el desarrollo económico y la prosperidad en estos países. Para conseguir el primer objetivo se propone un marco institucional común, con la finalidad de incentivar la participación de los vecinos del Sur en la definición de la política y reforzar el diálogo. Para alcanzar el segundo, se promueve la cooperación transregional en base a proyectos concretos en un número de sectores.

En el plano de las instituciones la UpM complementa el marco de la Asociación Euromediterránea con una copresidencia, que se ejercerá en todas las reuniones intergubernamentales, en manos tanto de la UE como de un país del Sur. También un Comité Permanente Conjunto, con sede en Bruselas, conformado por personal de las representaciones permanentes, encargado de los asuntos técnicos y de apoyar a los Altos Funcionarios. Los Altos Funcionarios, que sustituyen al antiguo Comité Euromed, reciben la misión de ocuparse de los asuntos políticos, del seguimiento de la política y de preparar las reuniones del Comité de Ministros. Finalmente, se crea una Secretaría propia con sede en el Palacio de Pedralbes en Barcelona, con la función de coordinar a todas las instancias políticas, poner en marcha y gestionar los proyectos y dar continuidad y permanencia a este nuevo organismo

\footnotetext{
${ }^{30}$ Sobre la evolución desde la propuesta de Sarkozy hasta el proyecto final de Unión por el Mediterráneo, véase: Bayón, David (2008): "La Unión por el Mediterráneo: al final, una etapa más del Proceso de Barcelona", UNISCI Discussion Papers, n 17, pp. 203-212.

${ }^{31}$ Asociación Euromediterránea, Declaración conjunta de la Cumbre de París por el Mediterráneo, Paris, 13 de julio de 2008 (EURO-MED 1/08).

${ }^{32}$ Granell, Francesc., "La Unión por el Mediterráneo como organismo internacional...", op. cit., pp. 1037-1039.

${ }^{33}$ Desde 2011, y como consecuencia de las sanciones adoptadas por la UE contra el régimen de Basher-el-Assad, Siria se ha retirado de la UpM.
} 
internacional. La Secretaría, que tiene carácter técnico, se encuentra dividida en Subsecretarías, organizadas en torno a los seis ámbitos de los proyectos ${ }^{34}$.

El enfoque de la UpM fue eminentemente pragmático: trabajar en torno a proyectos que unieran a las dos orillas del Mediterráneo y que promovieran el desarrollo económico, la cooperación regional y las interdependencias. Los seis proyectos inicialmente aprobados fueron: la descontaminación del Mar Mediterráneo; el establecimiento de autopistas marítimas y terrestres que permitan la libre circulación de personas y mercancías tanto por mar como por tren; programas de protección civil que ayuden a prevenir, proteger y responder a la población de los desastres naturales y de origen humano; el plan de energía solar mediterráneo; la Universidad Euromediterránea; y la Iniciativa de Desarrollo Empresarial Mediterránea. Si bien pretende un nuevo impulso al Proceso de Barcelona, desde el principio se criticó la ausencia de compromisos en algunos de sus ámbitos más relevantes, especialmente en el de seguridad ${ }^{35}$, pero también en la promoción de valores como la democracia y los derechos humanos y los asuntos comerciales y energéticos. Todos estos aspectos han seguido siendo abordados en los marcos bilaterales de la PEV.

La UpM ha tenido, hasta el momento, una difícil y corta vida: es un proyecto político que se queda sin contenido prácticamente al poco de nacer. Su lanzamiento coincidió en el tiempo con el estallido de la crisis económica, lo que ha hecho difícil la captación de recursos financieros, especialmente de capital privado, necesarios para la puesta en marcha de los proyectos $^{36}$. También se han visto afectados por tensiones geopolíticas y por la falta de interés de los estados miembros destinatarios. Aún así algunos proyectos ya comienzan a ver la luz, teniendo éxito principalmente los denominados soft, como la Universidad Euromediterránea y el apoyo a las PYMES, que no requieren de una excesiva financiación.

Desde el punto de vista político, la nueva institucionalización tampoco ha desplegado los efectos deseados, habiendo resultado especialmente dificultosa la puesta en marcha de la nueva Secretaría. En los primeros meses de vida de la UpM, en 2009, la causa fundamental de estas dificultades fueron las tensiones generadas por la ofensiva israelí en Gaza. Posteriormente, las Primaveras árabes, los consecuentes realineamientos y la transición institucional en la UE también ha sido obstáculos para el avance del diálogo político. Es especialmente llamativo que, desde su creación, no se haya convocado ninguna Cumbre en el nivel de Jefes de estado y de Gobierno, pero tampoco ninguna reunión ministerial de carácter oficial $^{37}$. A pesar de estos azarosos comienzos, hay algunas voces institucionales y entre los académicos que esperan que todavía esta iniciativa pueda dar relevantes frutos ${ }^{38}$.

\section{3. "Más por más": la reorientación de la PEV como consecuencia de las Primaveras Árabes}

La PEV sería profundamente reformada como consecuencia de las conocidas como "Primaveras Árabes", que desde diciembre del año 2010 afectarían en mayor o menor medida

\footnotetext{
34 Esos seis ámbitos son: empresa; energías renovables; asuntos sociales y protección civil; transporte; medioambiente y agua; e investigación, desarrollo y educación.

35 Marquina, Antonio (2009): "La Declaración conjunta en la Cumbre de París para el Mediterráneo. Un documento claramente mejorable en asuntos de seguridad", UNISCI Discussion Papers, nº 19, pp. 206-219.

${ }^{36}$ Véase sobre esta cuestión: Hunt, Diana (2011): "The UfM and Development Prospects in the Mediterranean: Making a Real Difference?", Mediterranean Politics, vol. 16, nº 1, pp. 171-192.

${ }^{37}$ En sus siete años de vida, en el marco de la UpM sólo se han reunido a los Ministros, con carácter informal en abril de 2015, a convocatoria de la Alta Representante Mogherini, con la finalidad de discutir sobre la revisión de la PEV.

${ }^{38}$ Granell, Francesc, "La Unión por el Mediterráneo como organismo internacional...", op. cit.
} 
a la práctica totalidad de los estados destinatarios de esta política en el Mediterráneo ${ }^{39}$. Para muchos autores, las "Primaveras Árabes" no dejan de ser una muestra del fracaso de las políticas europeas hacia el Mediterráneo y de la brecha existente entre la retórica y los hechos ${ }^{40}$. La prioridad de expandir la democracia ha quedado en cuestión al pactar la UE con Gobiernos autoritarios, en un intento de primar la estabilidad y la cooperación en asuntos de interés de los estados miembros, como la lucha contra el terrorismo y las migraciones. Igualmente la profunda crisis social y económica, que actuó como caldo de cultivo para los levantamientos, no deja de ser consecuencia del fracaso del objetivo de conseguir bienestar en la Orilla Sur del Mediterráneo, repetido una y otra vez desde los noventa. Las poblaciones del Mediterráneo sienten una gran frustración porque la política europea no les ha ofrecido la libertad, democracia, bienestar e identidad reforzada que prometía ${ }^{41}$.

La UE como entidad política, esto es, la Unión de los 27 estados en la época, no ha destacado por desarrollar un papel activo en estos procesos de cambio político. No se podía ocultar que en Mediterráneo sigue siendo un área donde los estados miembros tienen posiciones divergentes y no sólo respecto a los grandes temas de seguridad, sino también en relación a desafíos como la lucha contra el terrorismo o las migraciones ${ }^{42}$. La respuesta dada desde la PESC bien puede calificarse de titubeante, caracterizada por numerosas Declaraciones retóricas, ya sean del Consejo Europeo o de la Alta Representante para la $\mathrm{PESC}^{43}$. Los objetivos nacionales divergentes de los estados miembros impiden una respuesta colectiva eficaz. La UE, como tal, no ha desempeñado un rol activo ni en los procesos de cambio pacífico, ni en el caso de los virulentos como el de Libia y Siria. En el primer caso, algunos de los estados UE, Francia y el Reino Unido, al margen de la UE, obtuvieron del Consejo de Seguridad de las Naciones Unidas una Resolución favorable a la Responsabilidad de Proteger y lideraron, con el apoyo de la OTAN y otros estados miembros, una acción militar dirigida a derrocar al dictador Gadafi ${ }^{44}$.

La UE, liderada por la Alta Representante Ashton, se centraba en el apoyo económico y la reconstrucción postconflicto a través de la organización de un Grupo de Contacto, Conferencias de Donantes y la puesta en marcha de una operación Petersberg dirigida a apoyar a las autoridades libias en el control de sus fronteras ${ }^{45}$. Quedaba de manifiesto, una vez más, que los estados miembros sólo están dispuestos a que la UE se comporte como un actor

\footnotetext{
${ }^{39}$ Sobre las Primaveras árabes, véase: Brownlee, Jason, Masoud, Tarek y Reynolds, Andrew (2015): The Arab Spring: Pathways of Repression and Reform, Oxford, Oxford University Press; Davis, John (ed.) (2014): The Arab Spring and the Arab Thaw. Unfinished Revolutions and the Quest for Democracy, Farnham, Ashgate; Panebiando, Stefania y Rossi, Rosa (eds.) (2012): Winds of Democratic Change in the Mediterranean? Proccesses, Actors and Possible Outcomes, Soveria Manelli, Rubbettino.

${ }^{40}$ Sobre las crisis en los dos vecindarios, también en el Oriental y su vinculación a las políticas de la UE, véase: Rupnik, Jacques (ed.) (2014): Géopolitique de la démocratisation. L'Europe et ses voisinages, Paris, Presses de Sciences Po,

${ }^{41}$ Keukeleire, Stephan y Delreux, Tom (2008): European Union Foreign Policy, Basingstoke, PalgraveMacmillan, p. 265.

${ }^{42}$ Balfour, Rosa (2012): "EU Conditionality after the Arab Spring", Papers IEMed, n ${ }^{\circ}$ 16, June, p. 29; Echagüe, Ana., Michou, Hélène y Mikail, Barah (2011): "Europe and the Arab Uprisings: EU Vision Versus Member State Action", Mediterranean Politics, vol. 16, n 2, pp. 329-335.

43 Véase como ejemplo: Consejo Europeo, "Declaración del Consejo Europeo", Consejo Europeo extraordinario, 11 de marzo de 2011, (EUCO 7/11).

${ }^{44}$ Véase: Consejo de Seguridad de Naciones Unidas, Resolución 1973 sobre Libia, 17 de marzo de 2011 (S/RES/1973(2011)).

${ }^{45}$ La operación EUBAM Libia, se puso en marcha el 22 de mayo de 2013, con un mandato de dos años, que ha sido prorrogado, con la finalidad de apoyar a las autoridades libias en el logro de la seguridad en sus fronteras terrestres, marítimas y aéreas. Con el deterioro del conflicto sigue desarrollando sus actividades de formación y apoyo a las autoridades libias desde territorio tunecino. EEAS, Factsheet on EU Integrated Border Assistance Mission in Libya (EUBAM Libya), January 2015.
} 
civil de las relaciones internacionales y que, como mucho, extienda su actividad en materia de seguridad a la gestión de crisis y la reconstrucción postconflicto de tipo civil ${ }^{46}$. Este hecho no deja de esconder las diferencias existentes entre los estados miembros y, por tanto, la incapacidad de la UE para actuar como un actor estratégico ${ }^{47}$.

Las instituciones europeas responderían a las revoluciones árabes con una reforma de la PEV recogida en dos documentos sucesivos aprobados en la primavera de $2011^{48}$. En esta nueva estrategia común se propone reforzar la política en tres sentidos diferentes. El primero de ellos es incrementar los incentivos que hagan que los socios del Sur se comprometan con las reformas: más financiación, "más mercado", esto es, acuerdos comerciales más favorables, y movilidad de personas. En segundo lugar, se refuerza la bilateralización con un nuevo enfoque "más por más". Esto supondría un apoyo explícito mayor a la promoción de los valores de la democracia y los derechos humanos, con un refuerzo de la condicionalidad, por el cual aquellos países que presentaran resultados en sus transformaciones en la senda de la democracia y los derechos humanos, serían premiados con acceso a más financiación y a unas relaciones preferentes con la UE. Se potencia, en definitiva, el "enfoque regata", que conduce a diferentes relaciones con los estados del Sur, dependiendo de su compromiso con los valores de la UE. Tercero, se busca una mayor implicación europea con las sociedades civiles locales, como elemento fundamental para construir la "democracia profunda" perseguida.

Posteriormente, a finales de 2012, tenemos otra iniciativa que persigue también el relanzamiento de la cooperación con el Mediterráneo, una Comunicación de la Comisión que explícitamente apoya la integración regional en el Magreb ${ }^{49}$. Este elemento no hay que verlo como novedoso, sino que es absolutamente coherente con una de las características tradicionales de la política exterior europea que es el apoyo expreso a la regionalización de sus socios, a través de financiación y asistencia técnica ${ }^{50}$. En el pasado ya se había apoyado la puesta en marcha de la Unión Árabe del Magreb, que pronto perdió dinamismo por los problemas políticos de los socios. En este momento, se retoma esa línea de trabajo recodando como el impulso a la regionalización y la cooperación regional rinde frutos en términos de estabilización. Ese apoyo, además, se ha traducido en una incipiente cooperación reforzada de la UE con los países del Magreb en el marco de la vecindad en temas como diálogo político y seguridad, agricultura y medioambiente, industria, infraestructuras, comercio e inversión y desarrollo humano, que puede abrir nuevas vías de relación ${ }^{51}$.

\footnotetext{
${ }^{46}$ Véase en el mismo sentido: Koenig, Nicole (2014): "Between conflict management and role conflict: the EU in the Libyan crisis", European Security, vol. 23, n 3, pp. 250-269.

${ }^{47}$ Noutcheva, Gergana (2015): "Institutional Governance of European Neighbourhood Policy in the Wake of the Arab Spring", Journal of European Integration, vol. 37, n 1, pp. 19-36.

${ }^{48}$ Véanse respectivamente: European Commission /High Representative of the Union for Foreign Affairs, Joint Communication to the European Council, the European Parliament, the Council, the European Economic and Social Committee, and the Committee of Regions, "A Partnership for Democracy and Shared Prosperity with the Mediterranean", Brussels, 8.3.2011, (COM(2011) 200 final; European Commission /High Representative of the Union for Foreign Affairs, Joint Communication to the European Parliament, the Council, the European Economic and Social Committee, and the Committee of Regions, "A New Response to the Changing Neighbourhood", Brussels, 25.5.2011, (COM(2011) 303 final).

${ }^{49}$ Comisión Europea / Alta Representante de la Unión Europea para Asuntos Exteriores y Política de Seguridad, Comunicación conjunta al Parlamento Europeo, al Consejo, al Comité Económico y Social Europeo y al Comité de las Regiones "Apoyo al refuerzo de la cooperación y la integración regional en el Magreb: Argelia, Libia, Mauritania, Marruecos y Túnez", Bruselas, 17.12.2012, (JOIN(2012) 36 final).

${ }^{50}$ Véase en este sentido: Aldecoa Luzárraga, Francisco (2002): La integración europea. Análisis históricoinstitucional con textos y documentos. Vol. II. Génesis y desarrollo de la Unión Europea (1979-2002), Madrid, Tecnos, pp. 375-379.

51 Véase: European Commission, EU-Maghreb: First ministerial dialogue on closer regional cooperation, Brussels, 27.9.2013, (MEMO/13/831).
} 
La reacción europea se focalizó en los aspectos técnicos de la cooperación más que en una relación estratégica con los actores claves que permitirían influir en los acontecimientos de acuerdo con los intereses europeos ${ }^{52}$. Las instituciones poco podían hacer con las competencias de las que disponen: una vez más la capacidad de la UE de hablar con una sola voz y ofrecer una respuesta a las rebeliones árabes quedaba minada por su falta de competencias delegadas $^{53}$. La respuesta común ofrecida se acomoda al discurso normativo de la UE pero queda muy lejos de las necesidades y expectativas de los destinatarios y es irrelevante para incentivar el cambio ${ }^{54}$. Incluso, este enfoque puede resultar contraproducente si se aplicara de forma demasiado rígida, ya que corre el riesgo tanto de desincentivar reformas en el largo plazo, como de hacer perder protagonismo a la propia UE en la región ${ }^{55}$. En su aplicación, hasta el momento, se ha constatado, además, que se repite el tradicional "doble estándar": aunque se dice priorizar la democracia, en muchos casos se ha primado la estabilidad ${ }^{56}$.

Desde 2012, la Comisión ha comenzado a aplicar este enfoque ${ }^{57}$. Se crea así una Facilidad de la Sociedad Civil con un presupuesto de 26 millones de euros anuales, también un Foro de la Sociedad Civil, semejante al que ya existía para la Asociación Oriental. Se aplica el enfoque "más por más", duplicando en la práctica la financiación destinada a Túnez para apoyar la democracia y a otros estados según sus desarrollos. Se establecen directivas de negociación de Acuerdos de Libre Comercio con Egipto, Jordania, Marruecos y Túnez y se anuncian planes para negociar acuerdos de movilidad con Marruecos y Túnez. Sin embargo, la propia Comisión no puede dejar de reconocer que este giro de la política no es suficiente para evitar un deterioro visible de los estados de la vecindad, tanto en términos políticos, donde algunos estados han experimentado retrocesos en sus procesos de democratización, como en términos económicos, donde las perspectivas no han mejorado ${ }^{58}$. Es evidente que poco se puede hacer desde estos incentivos para enfrentar conflictos como el de Libia y Siria o situaciones en deterioro, desde el punto de vista democrático, como la de Egipto. Se constata, una vez más, una importante brecha entre las ambiciones de la UE y las capacidades de las que efectivamente dispone para aplicar su política ${ }^{59}$.

\footnotetext{
${ }^{52}$ Menon, Anand (2014): "The JCMS Annual Review Lecture "Divided and Declining? Europe in a Changing World"", Journal of Common Market Studies, vol. 52, Annual Review, pp. 5-24, p. 13.

${ }^{53}$ Börzel, Tanja A., Risse Thomas y Dandashly, Assem (2015): "The EU, External Actors, and the Arabellions: Much Ado About (Almost) Nothing", Journal of European Integration, vol. 37, no. 1, pp. 135-153.

${ }^{54}$ Tömmel, Ingeborg (2013): "The New Neighbourhood Policy of the EU: An Appropiate Response to the Arab Spring?", Democracy and Security, vol. 9, n 1-2, pp. 19-39.

${ }_{55}$ Völkel, Jan Claudius (2014): "More for More, Less for Less - More or Less: A Critique of the EU's Arab Spring Response à la Cinderella", European Foreign Affairs Review, vol. 19, nº 2, pp. 263-281..

${ }^{56}$ Dandashly, Assem (2015): "The EU Response to Regime Change in the Wake of the Arab Revolt: Differential Implementation", Journal of European Integration, vol. 37, $\mathrm{n}^{\circ}$ 1, pp. 37-56.

57 Véanse respectivamente: Comisión Europea / Alta Representante de la Unión Europea para Asuntos Exteriores y Política de Seguridad, Comunicación conjunta al Parlamento Europeo, al Consejo, al Comité Económico y Social y al Comité de las Regiones "Diseño de una nueva Política Europea de Vecindad", Bruselas, 15.5.2012 (JOIN (2012) 14); European Commission /High Representative of the Union for Foreign Affairs, Joint Communication to the European Parliament, the Council, the European Economic and Social Committee, and the Committee of Regions, "European Neighbourhood Policy: Working towards a Stronger Partnership ", Brussels, 20.3.2013, (COM(2013) 4 final).

${ }^{58}$ European Commission /High Representative of the Union for Foreign Affairs, Joint Communication to the European Parliament, the Council, the European Economic and Social Committee, and the Committee of Regions, "Neighbourhood at the Crossroads: Implementation of the European Neighbourhood Policy in 2013", Brussels, 27.3.2014, (COM(2014) 12 final), p. 3.

${ }^{59}$ Seeberg, Peter (2014): "Strategic Patience and EU Reform-Support. EU and the 'Arab Spring': The State of Play after Three Years", European Foreign Affairs Review, vol. 19, nº 3, pp. 453-470.
} 


\section{Una evaluación de la PEV: El gap entre las expectativas y resultados}

Once años después de la puesta en marcha de la PEV, ésta no ha logrado su objetivo fundamental, el de crear estabilidad en los estados vecinos a través de multiplicar las interdependencias económicas y sociales en un método típicamente monnetiano. Resulta evidente, a primera vista, que la situación en el Mediterráneo es globalmente peor que en el año 2003, con pocas excepciones. A nuestro juicio, diversos factores explican estas limitaciones. Si comenzamos examinando, la propia PEV, podemos suscribir la afirmación de Keukeleire y Delreux de que la PEV muestra un fracaso de la UE tanto en términos de objetivos, como de metodología, como de paradigma subyacente ${ }^{60}$.

En términos de objetivos, puede constatarse que tanto en el vecindario Este como en el Mediterráneo, la situación política y económica de muchos de los estados se ha deteriorado ${ }^{61}$. En la vecindad Sur, el entorno de seguridad ha empeorado drásticamente, con conflictos civiles, consecuencia de las revueltas árabes, como los de Siria y Libia, que amenazan directamente la seguridad europea. En casos como el de Egipto, se ha incrementado la inestabilidad. Y, en general en la región, se ha producido un preocupante incremento del terrorismo, de la presión migratoria y de los refugiados y de la delincuencia organizada vinculada a las migraciones. Incluso, en el caso de los estados que puedan considerarse exitosos, como Túnez, Marruecos o Jordania, es obligado reconocer que no son estados totalmente democráticos, respetuosos de los derechos humanos e inclusivos. Tampoco, con el incremento de relaciones con la UE, ha logrado aumentar su desarrollo y bienestar y extenderlo al conjunto de sus poblaciones. Luego es obligado constatar que, globalmente, siguen existiendo los mismos desafíos que al comienzo.

En segundo lugar, compartimos la idea del fracaso de la metodología de la política, en sus diversas capas generadas incrementalmente. Una política esencialmente normativa como la PEV tiene relevantes dificultades en la relación con unos países y sociedades que no comparten los valores sobre los que ésta se basa. Después del pasado colonial, la PEV es percibida por muchos de ellos como una nueva forma de "imperialismo suave", lo que dificulta que sea asumida por ellos, es decir, su "coapropiación"62. Igualmente, es preciso tener en cuenta las limitaciones en términos de financiación así como los otros incentivos, que no resultan suficientes para poner en marcha una reforma profunda en estas sociedades. Con la crisis del euro, además, se ha dificultado la capacidad de reforzar la financiación pública de la UE e, incluso, también la posibilidad de que los estados miembros aporten financiación bilateral a estos proyectos y la captación de recursos entre inversores privados ${ }^{63}$.

Finalmente, consideramos también que existe un problema fundamental con el paradigma subyacente a la política. Los estados destinatarios no están hoy día interesados en la cooperación europea. Ni la UE tiene hoy la fuerza moral necesaria como para que estos países se vean atraídos por sus valores, ni tampoco es hoy el único actor y proveedor de ayuda en el Mediterráneo, sino que compite duramente con otros actores emergentes y regionales en la zona. Se constata, además, que las grandes cantidades de dinero europeo empleados no sólo no han fomentado los ideales europeos sino que incluso se ha producido una evolución en sentido contrario, como es el crecimiento de la islamización en estos países. Los estados MENA, en definitiva, no se sienten atraídos por la UE como en el pasado sí lo fueron los del Centro y Este de Europa.

\footnotetext{
${ }^{60}$ Keukeleire, Stephen y Delreux, Tom, European Union Foreign Policy, op. cit., pp. 262-265.

${ }^{61}$ Véase al respecto: Rupnik, Jacques (ed.), Géopolitique de la démocratisation, op. cit.

${ }^{62}$ Hettne, Björn., "Interregionalism and World Order: The Diverging EU and US Models", op. cit., p. 114.

${ }^{63}$ Sobre la repercusión de la crisis en el actor internacional UE, véase: Kempin, Ronja y Overhaus, Marco (2014): "EU Foreign Policy in Times of the Financial and Debt Crisis", European Foreign Affairs Review, vol. $19, \mathrm{n}^{\circ} 2$, pp. 179-194.
} 
Más allá de la constatación de la falta de éxito de la PEV para alcanzar sus objetivos, queremos indagar qué factores explican el limitado éxito de esta estrategia política. Si examinamos los factores atribuibles al actor Unión Europea y su política exterior, en primer lugar, hay que mencionar la falta de coherencia del conjunto de políticas de la UE como actor internacional y la falta de rigor en la aplicación de la política de vecindad. Así, es difícilmente comprensible que se afirme promover la democratización, pero que se coopere activamente con Gobiernos autocráticos como ha ocurrido, aplicando un doble estándar ${ }^{64}$. Segundo, se ha detectado un excesivo idealismo en la formulación de la PEV, que no responde a la situación real de los estados destinatarios. En muchos casos se detecta un desconocimiento de las tendencias sociales de estos estados, como puede ser el auge social de los movimientos islamistas. En relación a la política, es preciso mencionar la falta de atractivo de los incentivos europeos para los estados de la orilla Sur. Atractivo que todavía disminuye más si se tiene en cuenta que la dependencia de estos estados respecto de la UE ha disminuido por la afluencia de otros actores internacionales de la cooperación que no aplican políticas de condicionalidad.

Detrás del fracaso de la política hay factores atribuibles a los propios estados miembros y que se derivan de la naturaleza compuesta del actor internacional UE. La PESC es intergubernamental, definida sobre el consenso, por lo que los estados miembros, sólo tienen una obligación de solidaridad política ${ }^{65}$. Por ello, en temas de alta política como la $\mathrm{PEV}$, la UE no actúa como un actor unitario y coherente. Esto explica, en buena medida, el hecho de que la PEV se haya formulado sobre la base de los valores, dado que la doctrina coincide en que tradicionalmente los valores han jugado en la PESC europea el papel de reforzar la cohesión entre los estados miembros ${ }^{66}$. Investigaciones empíricas han puesto repetidamente de manifiesto la discrepancia entre la política idealista formulada por la UE y las políticas que sus estados miembros promueven y desarrollan en la región ${ }^{67}$. Esto se traslada en agendas políticas que entran en competición y plantean un problema de coherencia de la política exterior europea y, lo que es más, minan la eficacia de cualquier acción colectiva europea a la vez que hacen que las políticas bilaterales sean cada vez más irrelevantes ${ }^{68}$.

El primer elemento que hay que destacar es que no todos los estados miembros muestran el mismo interés en cooperar con el Mediterráneo, ni defienden las mismas preferencias. En muchos de los asuntos candentes como el conflicto palestino-israelí, la amenaza terrorista o las migraciones defienden posiciones diferentes. Tradicionalmente, los estados que han impulsado la cooperación política y económica con el Mediterráneo han sido

\footnotetext{
${ }^{64}$ Baracani, Elena: "The European Neighbourhood Policy and Political Conditionality: Double Standards in EU Democracy Promotion?", en: Balzacq, Thierry (ed.) (2009): The External Dimension of EU Justice and Home Affairs. Governance, Neighbours, Security, Abingdon, Palgrave-Macmillan, pp. 133-153; Biscop, Sven y Borg, Stefan (2015): "A New Concept for a New Neighbourhood", en Florensa, Senen (dir.), The Arab Spring in Comparative Perspective, IEMed Joint Policy Study, March, pp. 80-92.

${ }^{65}$ Sobre las peculiaridades de un actor internacional de naturaleza compuesta, véase: Guinea Llorente, Mercedes (2010): "Innovación diplomática: la naturaleza de la Unión Europea como actor internacional", Sobrino Heredia, José Manuel (dir.), Alcaide Fernández, Joaquín, y Pureza, José Manuel (coords.), Innovación y conocimiento. Inovãçao e Conhecimento. IV Jornadas Iberoamericanas de Estudios Internacionales, Lisboa, 23,24 y 25 de noviembre de 2009, Madrid, Marcial Pons, pp. 437-444.

${ }^{66}$ Bretherton, Charlotte y Vogler, John (2006): The European Union as a Global Actor, Abingdon, Routledge, p. 43; Keohane Robert O. (2002): 'Ironies of Sovereignty: The European Union and the United States', Journal of Common Market Studies, vol. 40, no. 4, pp. 743-765; Matlary, Janne Haaland : 'Human Rights', en: Carlsnaes, Walter, Sjursen, Helene y White, Brian (eds.) (2004): Contemporary European Foreign Policy, London, Sage, pp. 141-154.

${ }^{67}$ Zajac, Justyna (2015): "The EU in the Mediterranean: Between its International Identity and Member States' Interests", European Foreign Affairs Review, vol. 20, nº 1, pp. 65-82.

${ }^{68}$ Witney, Nick y Dennison, Susi (2015): "Europe's Neighbourhood: crisis as the new normal", European Council on Foreign Relations Policy Memo, June, p. 6.
} 
los del Sur, con España y Francia a la cabeza. Presentan motivaciones clásicas de seguridad, comerciales, energéticas y pretenden consolidar vínculos históricos. Entre los del Norte en general se detecta falta de entusiasmo por la política euromediterránea, salvo los grandes como Alemania y Polonia que se han fijado tradicionalmente en su potencial como mercados secundarios $^{69}$. Sólo últimamente comienzan a introducir en sus agendas cuestiones relacionadas con la seguridad, e, incluso, éstas desde el punto de vista soft.

En segundo lugar, los estados miembros no tienen la voluntad política necesaria para asegurar el cumplimiento de los compromisos que han suscrito las instituciones europeas. Así, a título de ejemplo, aún cuando la UE se ha comprometido a negociar con algunos de los socios del Sur acuerdos de movilidad de personas, muchos de los estados miembros no están dispuestos a aceptarlos por miedo a un incremento de la presión migratoria legal. Por el contrario, son muchos los ejemplos de actuaciones de sus estados miembros en dirección contraria a lo acordado en el seno de la UE y que dañan irremisiblemente tanto la imagen de ésta, como su Política de Vecindad. Ejemplos de actuaciones bilaterales de algunos estados miembros, dañinas de los objetivos de la PEV pueden ser las estrechas relaciones entre Berlusconi y Gadafi, a pesar de las condenas formales del Consejo Europeo, o las de Francia con el líder tunecino Ben-Ali, incluso colaborando en las primeras represiones a los manifestantes.

Finalmente, no podemos dejar de mencionar el hecho de que, en muchas ocasiones, esta política no acaba en encajar con los intereses de las élites gobernantes, y que, muchas veces, las propias condiciones de los vecinos no permiten el éxito de la estrategia europea. El fracaso se explica por el compromiso formal de estos estados con las reformas pero la débil voluntad política de implementación real. Detrás de esa falta de implementación también se esconden problemas de corrupción y de gobernanza interna. También es preciso subrayar que, muchas veces, la financiación destinada a apoyar las reformas se queda sin aplicación, por la incapacidad para absorber los fondos de algunos de los destinatarios o de formular proyectos que encajen en lo dispuesto.

\section{La revisión de la política europea hacia el Mediterráneo}

Las instituciones europeas en los últimos tiempos han terminado por asumir la necesidad de reorientar y revisar en profundidad la PEV, tanto en su vertiente oriental como meridional, constatadas las limitaciones que tiene para alcanzar sus objetivos. La nueva Comisión Juncker, apenas cinco meses después de comenzar su mandato, en marzo de 2015, hacía público un documento de consulta con la finalidad de abrir un proceso de revisión de la $\mathrm{PEV}^{70}$. Se afirma expresamente que hay una necesidad clara de revisar las asunciones sobre las que se basa la política, así como su extensión, los diferentes instrumentos y las políticas que puedan contribuir mejor a la cooperación, reforzando los vínculos entre las prioridades internas y externas ${ }^{71}$.

Esa Comunicación buscaba servir de guía en un proceso amplio de consultas con todos los interesados, incluidos sectores gubernamentales y de la sociedad civil, tanto de los países

\footnotetext{
${ }^{69}$ Behr, Timo y Tiilikainen, Teija:"Conclusions", en: Behr, Timo y Tiilikainen,Teija (eds.) (2015): Northern Europe and the Making of the EU's Mediterranean and Middle East Policies, Farnham, Ashgate, pp. 201-202.

${ }^{70}$ European Commission /High Representative of the Union for Foreign Affairs, Joint Consultation Paper "Towards a New European Neighbourhood Policy", Brussels, 4.3.2015, (JOIN(2015) 6 final).

${ }^{71}$ European Commission /High Representative of the Union for Foreign Affairs, Joint Consultation Paper..., op. cit., p. 3.
} 
europeos como de los socios mediterráneos ${ }^{72}$. Con las aportaciones anteriores, la Comisión pretende lanzar una nueva iniciativa de reorientación de la PEV en el otoño de 2015. Partiendo de los escasos resultados de la PEV, sorprende que el documento de la Comisión abre todas las posibilidades para una posible revisión, incluido el propio modelo de PEV. Así comienza cuestionando si la PEV debe mantenerse como vía para construir relaciones estrechas con los países del entorno, y si debe aplicarse un marco común a los socios de los socios. Se cuestiona también sobre los destinatarios de la política, planteando la posibilidad de incluir a los vecinos de los vecinos ${ }^{73}$. Pregunta sobre cómo asociar más y con mayor efectividad a los estados miembros. Las ofertas de cooperación actualmente planteadas a los vecinos como los Acuerdos de Asociación y Libre Comercio Profundos y Comprensivos o los acuerdos de movilidad son también abordados, así como otras posibles alternativas. Se pregunta igualmente sobre la mecánica de la política y sus principales instrumentos, principios y mecanismos.

A tenor de este argumento, la Comisión asumiría un cambio de escenario, que junto al fracaso de la PEV, exigirían una reorientación de la política que conduce, incluso, al cuestionamiento de los cimientos sobre los que se asienta. La Comisión se plegaría así a las demandas de la práctica totalidad de la doctrina que, desde hace tiempo, vienen reclamando un giro completo de la política ${ }^{74}$. Sin embargo, no parece previsible que de este ejercicio vaya a salir un giro completo en la política exterior hacia la vecindad, ya que las instituciones con poder decisor, como el Consejo y el Parlamento, son partidarios del statu quo, aunque incluyendo pequeñas reformas para mejorar la eficacia.

El Consejo de Ministros da la bienvenida formalmente a la revisión y se asegura un lugar destacado para los estados miembros en ese proceso ${ }^{75}$. Subraya y se adhiere a todos los principios y características de la actual política, sin cuestionar ninguno, aunque llega a abrirse a considerar específicamente la cuestión de las relaciones con los "vecinos de los vecinos", como única novedad. Para el Consejo, las únicas reformas requeridas en este momento son aquellas que garanticen "la coherencia de la PEV y las dimensiones de seguridad y de política exterior de las acciones de la UE en el exterior", la racionalización de los procedimientos de concesión de ayuda y la mejora de la comunicación estratégica sobre la política. A nuestro juicio, esta lectura de las limitaciones de la política sólo puede calificarse de decepcionante, sin que los estados miembros estén a la altura de los desafíos.

\footnotetext{
${ }^{72}$ De hecho se ha utilizado el marco institucional de la UpM para desarrollar consultas con los socios sobre el futuro de la PEV. Así se convocó una reunión informal de Ministros de la Vecindad Sur sobre el futuro de la PEV el 13 de abril de 2014.

${ }^{73}$ Es preciso aclarar que este enfoque de extender el marco común a los vecinos de los vecinos a los que nos unen desafíos comunes ya es una realidad es la política exterior europea. Así, la Estrategia para el Sahel aprobada en 2011 establece los intereses en materia de seguridad y desarrollo para la UE en relación a tres países del Sahel (Malí, Mauritania y Níger) y establece cuatro líneas de acción común para abordarlos. Véase: European External Action Service, Strategy for Security and Development in the Sahel, March 2011.

${ }^{74}$ Véase, entre otros muchos: Balfour, Rosa (2014): "Not the European Neighbourhood Policy. Some iconoclastic tips to start rethinking the EU's relations with its neighbours", European Policy Centre Commentary, 12 December; Ben Ahmed, Ghazi., Faleg Giovanni. y Chiesa, Micol. A. (2014): M., "The End of Europe's Neighbourhood Policy", American Interest, 19 September; Foucher, Michel. y Lepesant, Gilles (2015): "Pour une nouvelle politique des voisinages", Fondation Robert Schuman Questions d'Europe, no 357, 18 Mai; Lehne, Stefan (2014): Time to reset the European Neighbourhood Policy, Brussels, Carnegie Europe; Tocci, Nathalie (2014): "The European Neighbourhood is Dead. What's Next for European Foreign Policy Along its Arc of Instability?, IAI Working Papers, $\mathrm{n}^{\circ}$ 14/16, November; Witney, Nick y Dennison, Susi., "Europe's Neighbourhood: crisis as the new normal", op. cit.

${ }^{75}$ Consejo de Asuntos Exteriores y Relaciones Internacionales, Conclusiones sobre la revisión de la Política Europea de Vecindad, Bruselas, 20.4.2015, (Press 118/15).
} 
El Parlamento Europeo, por su parte, en una Resolución de julio de 2015, también se muestra más conservador que innovador ${ }^{76}$. El Parlamento cuestiona y critica los resultados, pero no cuestiona ni los objetivos, ni la metodología 77 . Así afirma la necesidad de una "PEV revisada" que "sea capaz de proporcionar una respuesta rápida, flexible y adecuada a la situación real, proporcionando al mismo tiempo una visión estratégica ambiciosa (...) en consonancia con su compromiso de promover los valores esenciales en los que se basa la $\mathrm{PEV}^{78}$. El Parlamento se muestra convencido de que debe seguir siendo una "única política"79. Considera que su reto fundamental es "ofrecer mejoras tangibles y concretas a los ciudadanos de los países vecinos". Defiende que "debe convertirse en una política más fuerte, más efectiva y con un mayor carácter político, reforzando también sus elementos positivos, como una mayor atención por la asociación con las sociedades, la diferenciación y el enfoque "más por más""'80.

El Parlamento, al igual que el Consejo, se alinea con los elementos definitorios de la PEV actual: un único marco de relación, su carácter transformador, la transmisión de valores, la condicionalidad y la diferenciación. No ofrece, en su Resolución, prácticamente ningún aspecto innovador respecto a la actual política, sino que pone el énfasis en una mejora de la oferta de incentivos que la UE ponga a disposición de la $\mathrm{PEV}^{81}$. La crítica del Parlamento sólo puede ser calificada de superficial, ya que demanda, en el mejor de los casos, una reforma de la misma política, pero no la puesta en marcha de un nuevo modelo de relación. A nuestro juicio, la revisión de la $\mathrm{PEV}$ hacia el Mediterráneo debe ir mucho más allá, dado que el contexto en el cual se formuló ya no es el de hoy día, el paradigma se ha mostrado incorrecto y la política no ha mostrado sus frutos.

La región del Mediterráneo presenta hoy día numerosos retos de seguridad que no son comparables con los de hace doce años. Ya no tememos sólo los efectos desestabilizadores del irresuelto conflicto palestino-israelí o diversas amenazas de seguridad soft. Al día de hoy el Mediterráneo es un hervidero, que ha llevado hasta las mismas puertas de la UE cuestiones de seguridad hard vital para la UE, como la amenaza del estado Islámico en Siria, y crecientemente en Libia, presiones migratorias incontrolables que han hecho del Mediterráneo una gran tumba y todo tipo de tráficos y delincuencia internacional. Todo ello hace que la UE no pueda permitirse mirar hacia otro lado y tenga que dar una respuesta firme y clara, que debería incluir, en muchos casos, actuaciones en materia de seguridad. Sin embargo, los estados miembros de la UE parecen seguir siendo reacios a dotar a esta estructura supranacional de competencias para desarrollar las políticas de seguridad y defensa que necesita para ser un actor de referencia en el Mediterráneo.

Por muy graves que nos parezcan estas amenazas, sin embargo, en el seno de la UE no parece reinar un estado de ánimo favorable a hacer del Mediterráneo una prioridad absoluta

\footnotetext{
${ }^{76}$ Parlamento Europeo, Resolución sobre la revisión de la Política Europea de Vecindad, 9 de julio de 2015, (P8_TA(2015)0272).

${ }^{77}$ En otra Resolución, ésta sobre la PESC, afirma: "Insiste en la necesidad de revisar a fondo la política de la UE en lo que respecta a los países vecinos meridionales, la cual debe disponer de unos recursos presupuestarios adecuados e incluir el desarrollo y la aplicación de una estrategia global gracias a la cual los instrumentos y los medios de la UE se centren en apoyar la construcción de estados inclusivos que funcionen y que sean capaces de proporcionar seguridad a sus ciudadanos, promover la democracia, enfrentarse al extremismo religioso, respetar los derechos humanos, proteger a las minorías religiosas y étnicas y consolidar el estado de derecho...". Parlamento Europeo, Resolución sobre EL Informe anual de la Alta Representante de la Unión Europea para Asuntos Exteriores y Política de Seguridad al Parlamento Europeo, 12 de marzo de 2015, (P8_TA(2015)0075), pto. 39.

${ }^{78}$ Parlamento Europeo, Resolución sobre la revisión..., op. cit., pto. 1.

${ }^{79}$ Parlamento Europeo, Resolución sobre la revisión..., op. cit., pto. 2.

${ }^{80}$ Parlamento Europeo, Resolución sobre la revisión..., op . cit., pto. 3.

${ }^{81}$ Parlamento Europeo, Resolución sobre la revisión..., op. cit., pto. 6 y ss.
} 
de la política exterior. Además de reticentes, los estados miembros están lejos de compartir una visión común sobre los objetivos e intereses que esta política debe perseguir ${ }^{82}$. Ya la Unión ampliada había girado su atención hacia el Este de Europa, lo que hoy día se ha agudizado con el conflicto de Ucrania y las dificultades de la relación con Rusia y sus implicaciones para los abastecimientos energéticos europeos. Hay que tener en cuenta, además, que quienes han impulsado la atención europea sobre el Mediterráneo han sido los estados que se encuentran más próximos, los estados del Sur de Europa. Francia, Italia y España han experimentado una pérdida de peso específico dentro de la UE consecuencia de los realineamientos causados por la crisis financiera y económica ${ }^{83}$. Carecen, en este momento, tanto de los recursos financieros necesarios como del peso político como para enganchar al conjunto de la Unión, lo que explica, en buena medida, la pérdida de interés de la UE.

La PEV se formula en un contexto histórico que poco o nada tiene que ver con el actual. En 2003, bajo el paraguas del proveedor de seguridad de Estados Unidos y consecuencia tanto de los vínculos históricos de sus estados miembros, como de las políticas exteriores comunitarias, la UE era un referente para los estados MENA, tanto en términos comerciales como de cooperación política. Sin embargo, desde 2011 el escenario del Mediterráneo ha cambiado radicalmente como consecuencia de varios factores: la Primavera Árabe y los conflictos desencadenados, la crisis europea y su pérdida de peso internacional, el ascenso de la influencia de actores emergentes como Rusia y China y la creciente presencia de los estados del Golfo. Todo ello hace que la UE ya no sea el único referente para MENA, sino que entra en competencia con otros actores con fuerte y creciente presencia, lo que recorta su capacidad de influencia ${ }^{84}$.

Desde 2010 Rusia ha incrementado sustancialmente su presencia en el Mediterráneo, a través de vínculos comerciales y acuerdos de cooperación política, influencia que se ha visto radicalmente reforzada con el conflicto sirio y la anexión de Crimea, que ha supuesto un despliegue naval permanente en el Mediterráneo ${ }^{85}$. China, en los últimos quince años, se ha ido progresivamente consolidando como un actor económico y político clave para el Mediterráneo. Si bien comienza su penetración interesándose por las materias primas de estos países, hoy es un socio relevante en términos comerciales y de la cooperación para el desarrollo. Si bien tradicionalmente, la influencia de Turquía y los estados del Golfo en el Mediterráneo se debía a motivaciones económicas, desde las Primaveras Árabes algunos de estos estados han consolidado su peso político. Así, Qatar ha sido un actor relevante para el inicio de las revoluciones de Túnez, Egipto, Libia y Siria ${ }^{86}$. Arabia Saudí ha luchado contra los Hermanos Musulmanes en Egipto y otros estados y ha apoyado a las monarquías jordana, marroquí y de otros estados del Golfo. Kuwait y otros estados del Golfo han financiado a la

\footnotetext{
${ }^{82}$ Kochenov, D., "New Developments in the European Neighbourhood Policy...", op. cit., p. 582.

${ }^{83}$ Como consecuencia de las turbulencias internas que ha supuesto la crisis financiera y económica para la UE se constata un cambio en las dinámicas de poder entre los estados miembros, habiendo salido fortalecidos aquellos que gozan de una mayor estabilidad financiera interna, todos ellos países del Norte, con Alemania a la cabeza. Véase al respecto: Guinea Llorente, M. (2014): "Las consecuencias de la crisis económica para el modelo político de la Unión Europea: profundización, diferenciación y demandas de legitimidad", en VVAA, Cursos de Derecho Internacional y Relaciones Internacionales de Vitoria-Gasteiz 2013, Cizur Menor, Thomson-Reuters Aranzadi, pp. 273-365.

${ }^{84}$ Véase en relación a esta cuestión: Marquina, Antonio: "El Mediterráneo en la Estrategia de Seguridad Nacional 2013", en Marquina, Antonio (ed.) (2015): La Estrategia de Seguridad Nacional 2013. Un pavimento deslizante, Madrid, UNISCI, pp. 127-156, esp. las pp. 133-155.

${ }^{85}$ Véase en este mismo número el trabajo de Antonio Alonso y Ma Isabel Nieto, "Rusia en el Magreb ¿Un nuevo competidor para la UE?".

${ }^{86}$ Véase en este mismo número el trabajo de Alberto Priego sobre "Las Primaveras Árabes: la influencia de Qatar y sus relaciones con los estados del Golfo".
} 
oposición a Bashar-el-Asad en Siria. Ese peso político, además, se ha consolidado con relevantes fondos de cooperación procedentes de estos países que apuntan a consolidar y apoyar a los gobiernos de la zona.

Aprovechando la doble crisis, financiera y de modelo, de la UE, otros actores internacionales se han ido consolidando como referentes y socios estables de la cooperación en el Mediterráneo. Esto cuestiona la propia mecánica y efectividad de la PEV, ya que si los MENA obtienen de estos estados recursos para desarrollarse sin condiciones ni discusión sobre el liderazgo de las élites, la condicionalidad no tendrá objeto. Igualmente hay que tener en cuenta la dificultad de que los MENA se sientan identificados con los valores que se les proponen desde la $\mathrm{PEV}$, mientras que por las afinidades religiosas y culturales comparten más fácilmente valores con estados como los del Golfo y Turquía. Este desplazamiento de poder en el Mediterráneo recomienda, por tanto, un cambio en la mecánica de la política, si se quieren resultados.

No obstante, desde las instituciones de la UE tendrán que barajarse cuidadosamente la manera en que se combinen la promoción de los valores con la consecución abierta de los intereses europeos. No podemos olvidar en este punto, como el propio Tratado de la UE obliga en su artículo 21 a que todas las políticas exteriores que se desarrollen sirvan a la promoción de la democracia y los derechos humanos. Luego, la efectividad de la política debe buscarse también por otros cauces, pero sin desdibujar su carácter normativo. La cuestión que se nos plantea aquí es si se puede tener un actor internacional sólido y creíble desarrollando solamente políticas esencialmente normativas.

Finalmente, otra cuestión que habrá de abordarse es la de los destinatarios de la política. Estudios empíricos demuestran que el vecindario sur se está fragmentando y diversificando crecientemente, tanto desde el punto de vista económico como político y, especialmente, si tenemos en cuenta el tipo de relación que los diferentes estados MENA quieren con la $\mathrm{UE}^{87}$. Por ello, mantener un marco homogéneo que tenga como destinatarios a los diez MENA, aunque se persiga la diferenciación, hoy día carece de sentido. Por el contrario, deberían perseguirse un modelo más flexible con diversos marcos de cooperación diferenciada, adaptados a la singularidad de cada país o conjunto de países y a sus aspiraciones respecto a la UE. En este último sentido, se baraja la posibilidad de incentivar la cooperación interregional, privilegiando el Magreb, en el sentido de los últimos pasos dados desde la Comisión. Incluso, desde la teoría, se baraja la posibilidad de que se planteen modelos de cooperación reforzada o diferenciada entre un grupo de estados miembros y un grupo de MENA, siguiendo la primera propuesta de Unión Mediterránea de Sarkozy.

La reforma de la PEV en su conjunto, y no sólo hacia el Mediterráneo, está en curso, demostrada la ineficacia de las sucesivas capas que se han puesto en marcha desde el año 2003. Tanto la inercia de las instituciones, como el escaso interés de los estados miembros indican que la revisión será menor, sin que se lleguen a enfrentar los desafíos del Mediterráneo. Y es que estos no encuentran respuesta en el estrecho marco de los Tratados, que no dan a la UE los instrumentos suficientes para que sea un actor efectivo de las relaciones internacionales.

\section{Conclusiones}

El Mediterráneo es, hoy más que nunca, un área prioritaria para la UE, donde se ponen en juego intereses vitales de seguridad. No podemos obviar el riesgo directo que conflictos como

\footnotetext{
${ }^{87}$ Kausch, Kristina (2013): "The End of the (Southern) Neighbourhood", Papers IEMed, no 18, April, p. 41.
} 
el de Siria y el de Libia entrañan para el incremento de la amenaza terrorista en el seno de la UE. Por ello, el incremento y la mejora de la cooperación con estos países es un objetivo irrenunciable para poder preservar la seguridad y el bienestar de los europeos, aunque parece que flaquee la voluntad política de algunos de sus estados miembros. En la actualidad la UE se encuentra en un proceso de revisión de la PEV, pero es imprescindible que se realice en paralelo y vinculada a la revisión estratégica general de la Política Exterior y de Seguridad Común, también en curso ${ }^{88}$.

La PEV, tal y como ha sido formulada y aplicada hasta el día de hoy, es un marco homogéneo para tratar situaciones heterogéneas y demasiado diversas entre sí, que no ha funcionado. Se ve clara la necesidad de partir las dos lógicas y formular políticas adecuadas a las distintas situaciones. En lo que se refiere al Mediterráneo, el modelo subyacente de la PEV no nos parece adecuado para enfrentar los desafíos actuales por varias razones que hemos visto. En primer lugar, no se cumple el paradigma de que los valores europeos sean un modelo de referencia para los MENA. Y, si a esto le sumamos el poco interés que para ellos tienen los incentivos de la PEV, vemos el poco atractivo que para ellos tiene el estatuto de vecinos. Los MENA no cuentan tampoco con las estructuras políticas, económicas y sociales necesarias para que pueda implementarse eficazmente la PEV. Se trata de un marco demasiado exigente que no puede competir con los recursos ofrecidos por los otros actores internacionales, con presencia creciente en el Mediterráneo.

La UE tiene el desafío de lograr una política más inclusiva y más eficaz, que logre construir seguridad y estabilidad en el Mediterráneo. Se encuentra, sin embargo, con una serie de limitaciones difícilmente superables. En primer lugar, no cuenta con todos los instrumentos y herramientas necesarios, sobre todo, en materia de seguridad, ya que no ha recibido esas competencias de sus estados miembros. Por otro lado, tampoco puede renunciar a la promoción de sus valores, por imperativo del Tratado. Los estados miembros europeos, por tanto, tienen ante sí el dilema de poner en común los recursos y competencias para hacer una verdadera política exterior que resulte atractiva para los MENA y sea capaz de generar seguridad y bienestar en el Mediterráneo sin renunciar a los valores. Para ello, no pueden defender el statu quo, sino que tendrán que considerar la puesta a disposición de la UE de todas las herramientas necesarias, cambiando incluso el Tratado.

\footnotetext{
${ }^{88}$ El Consejo Europeo ha encargado a la Alta Representante y Vicepresidenta de la Comisión, Federica Mogherini, que desarrolle un proceso de reflexión estratégica para preparar una estrategia global para la Política Exterior y de Seguridad Común, que deberá culminar en junio de 2016. Véase: Consejo Europeo, Conclusiones de la Presidencia, Bruselas, 25 y 26 de junio de 2015, (EUCO 22/15), pto. 10.
} 